\title{
A Review of the Efficacy and Tolerability of Combination Amlodipine/Valsartan in Non-White Patients with Hypertension
}

\author{
Keith C. Ferdinand • Samar A. Nasser
}

Published online: 20 June 2013

(C) The Author(s) 2013. This article is published with open access at Springerlink.com

\begin{abstract}
This article discusses racial/ethnic disparities in hypertension, with particular focus on non-white populations including blacks, Hispanics/Latinos, and Asians. Hypertension and its related morbidity and mortality affect a disproportionate number of black patients compared with white patients. Blacks, Hispanics/Latinos, and Asians have poor rates of hypertension awareness, treatment, and control. Given the high prevalence of comorbidities (e.g., obesity, diabetes, and metabolic syndrome) in these populations, renin-angiotensin-aldosterone system blockers are a good choice for foundation therapy. This review also discusses the importance of adherence and persistence with antihypertensive medication, which remain suboptimal in these non-white populations. Evidence suggests improvement with the use of single-pill combination therapy. Lastly, clinical trial data on the antihypertensive efficacy and safety of the combination of a dihydropyridine calcium channel blocker and an angiotensin receptor blocker, a widely utilized combination, in non-white populations are presented. PubMed was searched using the title/abstract key words (amlodipine AND valsartan AND [hypertension OR hypertensive] AND [black(s) OR African American(s) OR Hispanic(s) OR Latino(s) OR Mexican(s) OR Asian(s)]). In total, eight studies in patients with stage 1 or
\end{abstract}

\footnotetext{
K. C. Ferdinand $(\square)$

Division of Cardiology, Tulane University School of Medicine, and Association of Black Cardiologists, Inc.,

1430 Tulane Ave., SL-48, New Orleans,

LA 70112, USA

e-mail: kferdinand@abcardio.org

S. A. Nasser

UM-Dearborn/Oakwood Healthcare Research Partnership,

The University of Michigan-Dearborn School of Education,

Dearborn, MI, USA
}

2 hypertension were identified ( $n=1,111$ black, $n=389$ Hispanic/Latino, and $n=3,094$ Asian). Results showed that treatment with the combination of amlodipine plus valsartan is a reasonable choice for initial therapy or in patients who fail to respond to monotherapy. These drug classes have complementary mechanisms of action and, when used concomitantly, the magnitude of blood pressure lowering in these non-white populations is generally comparable with that seen in non-Hispanic white patients.

\section{Introduction}

Approximately 68 million American adults aged 18 years or older (31\% of the total population) have hypertension and thus are at an increased risk for cardiac events [1]. Notably, hypertension is the most common risk factor for cardiovascular disease (CVD), exceeding diabetes mellitus, obesity, dyslipidemia, and smoking [2]. Uncontrolled hypertension specifically leads to increased fatal and nonfatal stroke and myocardial infarction (MI), along with heart failure and chronic kidney disease [3]. With estimated costs exceeding US $\$ 300$ billion in 2009, CVD accounts for the single largest proportion of both direct and indirect US health care costs annually [2]. Furthermore, by 2030, direct medical costs alone are projected to exceed US\$800 billion annually.

A meta-analysis of approximately 1 million adults including 61 prospective observational studies demonstrated an absolute increase in cardiovascular risk that doubles for each $20 / 10 \mathrm{mmHg}$ increase in systolic/diastolic blood pressure (BP) $[4,5]$. On the other hand, antihypertensive therapy with appropriate reduction in BP has been shown to reduce this increased risk. For each 2-, 3-, and $5-\mathrm{mmHg}$ systolic BP reduction, there is a risk reduction in 
stroke mortality of 6,8 , and $14 \%$, respectively, and a risk reduction in coronary heart disease mortality of 4,5 , and $9 \%$, based upon an analysis of five large population studies [6].

Unfortunately, over $50 \%$ of patients with hypertension are uncontrolled and, although there has been an increase in improvement of control over the last several years, National Health and Nutrition Examination Survey (NHANES) data have shown that many patients with hypertension remain at increased risk [7]. Various factors resulting in lack of BP control include the asymptomatic nature of elevated BP in many patients, non-adherence to therapy, and therapeutic inertia. Therefore, achieving adequate BP control involves improved systems for patient adherence, including education and counseling, team-based approaches, and the use of combination therapy with agents from complementary classes, especially in high-risk patients with stage 2 hypertension.

The objective of this article is to discuss racial/ethnic disparities in hypertension, with particular focus on nonwhite populations including blacks, Hispanics/Latinos, and Asians. In addition, the importance of adherence and persistence with antihypertensive medication and the benefits of single-pill combination (SPC) therapy are described. Clinical trial data on the antihypertensive efficacy and safety of the combination of a dihydropyridine calcium channel blocker and an angiotensin receptor blocker, a widely utilized combination, in the above populations are also presented.

\section{Disparities in Hypertension}

Cardiovascular risk varies based on race/ethnicity. Although demographic terms are not scientifically based terms, the recognition of differences in hypertension control by race and ethnicity allows clinicians to target populations in need of improved care.

\subsection{Blacks}

African Americans or non-Hispanic blacks have one of the highest rates of hypertension in the world with an increased likelihood of cardiovascular morbidity and mortality $[2,8]$. It is well known that hypertension is perhaps the most significant contributor to the mortality gap between African Americans and white Americans [4]. Recent NHANES data (2009-2010) showed that the overall age-adjusted prevalence of hypertension in African Americans was approximately $41 \%$ compared with $28 \%$ in non-Hispanic whites [9]. African Americans develop hypertension more often, at an earlier age, and present with more severe hypertension than whites [2, 8]. Thus, overall, African
Americans have worse BP-related outcomes compared with whites, including greater rates of mortality, stroke, left ventricular hypertrophy, heart failure, chronic kidney disease, and end-stage renal disease $[2,8,10]$.

African Americans also have a high prevalence of obesity, diabetes, and hypercholesterolemia. Analysis of NHANES data showed that age-adjusted rates of obesity increased from $32.0 \%(1988-1994)$ to $42.4 \%$ (19992004) among African Americans [11]. In comparison, nonHispanic whites had an obesity prevalence of 22.8 and $30.8 \%$ during the same time periods, respectively. The age-adjusted prevalence of diabetes in African Americans increased from $11.5 \%$ in 1988-1994 to $13.0 \%$ in 1999-2004, while that of hypercholesterolemia declined but remained high (from 54.2 to $50.5 \%$ ). The presence of comorbid conditions in hypertensive African Americans adds to the difficulty in managing these patients.

\subsection{Hispanics/Latinos}

The term Hispanic is a demographic term for a person of Spanish descent, regardless of race. NHANES primarily studied Mexican Americans and found that, although rates of hypertension were not higher versus whites, this population had the greatest likelihood of not being aware of the presence of hypertension, had less treatment of elevated BP, and had less BP control [7, 9, 12]. However, according to another recent study, involving middle-aged and older adults aged 45-84 years (mean age 59 years), Carson and colleagues demonstrated that the crude incidence rate of hypertension per 1,000 person-years was higher in Hispanics compared with non-Hispanic whites (65.7 vs. 56.8 ) [13]. Therefore, the recognition of poorly controlled hypertension across various populations is an important component of decreasing overall CVD and disability in the USA.

The Hispanic Latino population in the USA has increased dramatically over the past few decades, and several studies have demonstrated that this population has a higher cardiovascular risk compared with non-Hispanic whites [14, 15]. Recently, a multicenter, prospective, population-based study indicated that the prevalence of major cardiovascular risk factors, including hypertension, varies across the diverse Hispanic/Latino backgrounds in the USA. The Hispanic Community Health Study/Study of Latinos included 2,201 Cuban, 1,400 Dominican, 6,232 Mexican, 2,590 Puerto Rican, 1,634 Central American, and 1,022 South American adults aged 18-74 years (mean age 43 years) [16]. The prevalence of hypertension ranged from $19.9 \%$ (South American) to $32.6 \%$ (Dominican) in men and from $15.9 \%$ (South American) to $29.1 \%$ (Puerto Rican) in women. However, use of antihypertensive medication was low $(\sim 15 \%)$ in both men and women, ranging 
from $10.7 \%$ (South American) to $18.4 \%$ (Dominican) among men and from $8.4 \%$ (South American) to $18.8 \%$ (Dominican and Puerto Rican) among women. In men and women, high rates of obesity (36.5 and $42.6 \%$, respectively) and hypercholesterolemia (51.7 and $36.9 \%$ ) were noted, and there were positive associations between increased stroke and poorly controlled BP in age-adjusted analyses.

One reason for the disparities noted in the Hispanic/ Latino population regarding lack of BP control and lesser awareness and treatment of BP may be the lack of evidence-based guidelines for this minority population [17]. The Hispanic paradox, despite evidence against it [18], is another likely contributing factor. As a result, treatment of hypertension may not be taken as seriously in this population. Additionally, given the high prevalence of other cardiovascular risk factors (i.e., obesity, diabetes, hypercholesterolemia, and metabolic syndrome) in the Hispanic/ Latino population, these individuals are likely to require multiple agents to adequately control their BP and minimize the risk of cardiovascular complications $[2,11]$.

\subsection{Asians}

Asians represent the largest racial group in the world. The prevalence of hypertension in China, the most populated country in the world, has increased rapidly over the past decade, from rates of approximately $20 \%$ in 2000 [19] to more than one third, based on more recent estimates [2023]. For example, a cross-sectional study of 5,760 adults in Beijing, China, showed a high prevalence of hypertension (35.5\%), with similar rates in both urban and rural communities [21]. In Korea, Thailand, and Taiwan, the prevalence of hypertension is lower, but is also expected to increase from 14.5-17.0 \% in 2000 to $17.1-18.8 \%$ in 2025 [19]. In the Beijing study, only $42.5 \%$ of hypertensive patients were aware of their disease, $35.9 \%$ were undergoing treatment, and $11.8 \%$ had their BP controlled [21]. A similar pattern was reported in other surveys [20, 22, 23]. These rates are lower than those found among blacks and Mexican Americans, based on recent NHANES data [9].

As seen in blacks and Hispanics/Latinos, hypertension is often present with other comorbid conditions in the Asian patient. Diabetes, in particular, occurs often in the Asian population, and develops at an earlier age relative to Westerners [24]. Qin and colleagues [25] reported that the prevalence of previously undiagnosed diabetes was $9.8 \%$ among 17,184 Chinese hypertensive adults aged 45-75 years; $3.4 \%$ had previously diagnosed diabetes and another $14.1 \%$ had impaired fasting glucose. In another large cross-sectional study, nearly one third of 19,003 adults surveyed in Beijing were overweight or obese and, among obese individuals, the prevalence of hypertension ranged from $34.8 \%$ (body mass index [BMI] of $\left.30-34.9 \mathrm{~kg} / \mathrm{m}^{2}\right)$ to $50.7 \%\left(\mathrm{BMI}>40 \mathrm{~kg} / \mathrm{m}^{2}\right)$ [26]. Similar trends were noted for diabetes and metabolic syndrome [26]. Thus, treatment with a single antihypertensive agent is unlikely to achieve the BP goals for a majority of these high-risk patients.

\section{Implications of Adherence and Persistence to Antihypertensive Therapy}

Using a hypertension registry at Kaiser Permanente of Northern California, a retrospective analysis of 44,167 adults greater than or equal to 18 years of age (84\% $\leq 64$ years) demonstrated variation in persistence and adherence among sociodemographic groups [27]. More than $30 \%$ of patients were non-persistent early on (i.e., failed to refill first prescription within 90 days), with one in five non-adherent to therapy $(<80 \%$ of days covered during the 12 months following start of treatment). Suboptimal medication-taking behavior was more likely in non-whites compared with whites. Using regression models for various factors, non-white race was associated with non-persistence (black odds ratio 1.56 [95\% confidence interval 1.43-1.70]; Asian 1.40 [1.29-1.51]; Hispanic 1.46 [1.35-1.57]) and non-adherence (black 1.55 [1.37-1.77]; Asian 1.13 [1.00-1.28]; Hispanic 1.46 [1.31-1.63]). Interestingly, racial/ethnic differences in non-adherence were lessened when medication co-payment and mail-order pharmacy (both aiding ease of use) were factored into the model. These data suggest that health system strategies that reduce patient co-payments, improve access to medications, and optimize the choice of initial therapy may help reduce persistent gaps in the use of clinically effective therapies.

\section{Benefits of Single-Pill Combination Therapy}

In view of the high rates of uncontrolled hypertension in African Americans, Hispanics/Latinos, and Asians, optimal therapy along with medication adherence and persistence are important. Evidence suggests that the majority of patients with hypertension will require combination therapy to reach their BP goals [4]. Antihypertensive regimens that are less complex have been shown to improve medication adherence and persistence [28, 29]. Combination therapy is appropriate either as an SPC (i.e., multiple agents in a single pill) or free combination (FC) (i.e., multiple agents as separate pills). A study of 7,224 patients demonstrated that SPC therapy over 12 months was associated with better persistence $(42.5 \%$ higher; $P<0.002)$ 
and adherence $(22.1 \%$ higher; $P<0.001)$ compared with that seen in patients who were switched to FC therapy [30]. Better adherence and persistence are likely to improve upon positive health benefits through enhanced hypertension control and positive economic benefits through lower costs for hypertension-related health care.

In addition to improved adherence and persistence, combination therapy in the management of hypertension allows for a reduction in BP variability [31]. Short- and long-term effects of BP variability are associated with an increased risk of both renovascular and cardiovascular events and mortality [32]. Evidence suggests that combination therapy, particularly the addition of a calcium channel blocker or diuretic to a renin-angiotensin-aldosterone system (RAAS) blocker, is associated with less BP variability, which may improve outcomes [31, 33]. Furthermore, in a meta-analysis of 42 trials, Wald and colleagues [34] demonstrated that combining antihypertensive drugs from two different classes lowered BP five times more than doubling the dose of one agent. Of note, given that there are lower dosage requirements in combination therapy for each individual agent and the fact that combination therapy can provide additive or synergistic BP lowering, the result may lead to a reduction in side effects, thus improving compliance [33]. Therefore, the use of an SPC may translate directly to achievement of BP goals more quickly with attenuation of adverse drug reactions.

SPCs appear to improve compliance especially if differences in acquisition costs can be controlled. In a retrospective cohort study, Malesker and Hilleman [35] evaluated clinical and economic outcomes in patients using an SPC of amlodipine/valsartan versus the outcomes from conventional combination therapy. In the SPC cohort, $58 / 100$ patients $(58 \%)$ achieved BP targets, compared with $47 / 100$ control patients $(47 \%)(P=0.119)$, and the absolute reduction in systolic/diastolic BP was significantly greater in the SPC group $(22.8 \pm 6.9 / 19.3 \pm 5.2 \mathrm{mmHg})$ than in the control group $(20.6 \pm 6.4 / 17.8 \pm 5.6 \mathrm{mmHg})$ $(P \leq 0.03)$. Overall, in the SPC cohort, there were significantly fewer patients who discontinued their antihypertensive therapy because of side effects and non-compliance compared with the control group (both $P=0.042$ ). Even though the SPC patients had higher medication acquisition costs (US\$479 vs. US\$367), they accrued fewer clinic visits, laboratory tests, and electrocardiograms, thus translating into a reduction in comprehensive medical treatment costs over the 6 months of follow-up. Specifically, health care resource utilization costs per patient totaled US\$2,734 with the SPC and US\$3,490 in controls $(P=0.024)$. Total health care costs were similarly lowered (16-20\% reduction) with the SPC of amlodipine/ valsartan compared with calcium channel blocker/angiotensin receptor blocker FC therapy $(P<0.0001)$ [36].
Of note, the cost of SPC therapy to the patient has the potential to be lower since only a single copayment is necessary, compared with multiple copayments for FC therapy [37]. Lower copayments may have the added benefit of improved adherence and persistence with hypertension medication [38].

\section{Focus on Combination Amlodipine/Valsartan in Non-Whites with Hypertension}

Results of several studies suggest that some RAASblocking drugs manifest diminished average BP responses in black patients relative to other drug classes (i.e., calcium channel blockers, thiazide diuretics) [39-41]. However, the use of multiple antihypertensive agents has been shown to offset any racial/ethnic differences in response to therapy [42]. Moreover, RAAS pharmacological blockade provides greater cardiorenal protection than other non-RAAS drug classes [43-45]. A major renoprotective effect is demonstrated with ramipril in African Americans with hypertensive nephropathy, a group at risk for more rapid loss of kidney function over time [10, 46]. Hispanics/Latinos and Asians with hypertension are also likely to benefit from the use of RAAS inhibitors, especially given that these patients pose a challenge to BP control secondary to their high prevalence of other cardiovascular risk factors such as obesity, diabetes, and metabolic syndrome. Thus, there is a good rationale for the use of RAAS inhibitors as foundation therapy in these high-risk patients, with diuretic or calcium channel blocker added as needed.

Dihydropyridine calcium channel blockers and angiotensin receptor blockers have complementary mechanisms of action (Fig. 1) [47], and each of these drug classes is recommended in the prevention and/or treatment of most complications of hypertension (Fig. 2) [48]. The following sections and Table 1 summarize the results of studies with combination amlodipine/valsartan in non-white populations with hypertension, with a focus on blacks, Hispanics/ Latinos, and Asians. Since these drugs are widely utilized in the USA in hypertension pharmacotherapy, these particular agents, representing the dihydropyridine calcium channel blocker and angiotensin receptor blocker drug classes, will be the main focus of discussion. Both valsartan and amlodipine have been extensively studied, with a wealth of BP and outcomes data [49-52].

A search of PubMed was conducted through to 25 February 2013, using the title/abstract key words (amlodipine AND valsartan AND [hypertension OR hypertensive] AND [black(s) OR African American(s) OR Hispanic(s) OR Latino(s) OR Mexican(s) OR Asian(s)]). This search revealed a total of 19 articles in the English language. A review of the abstracts from this search 
Fig. 1 Complementary mechanisms of action (MOA) of dihydropyridine calcium channel blockers (CCBs) and angiotensin receptor blockers (ARBs) in lowering blood pressure (BP). Reprinted from Neutel [47], with permission from JTE Multimedia
ARB MOA

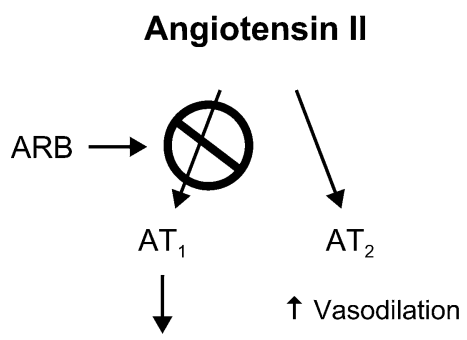

$\downarrow$ Vasoconstriction $\downarrow$ Aldosterone secretion

$\downarrow$ Catecholamine release

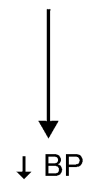

AT, angiotensin; $\mathrm{Ca}++$, calcium.

CCB MOA

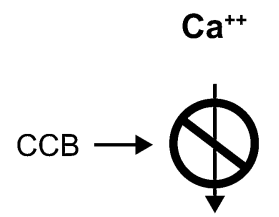

L-type $\mathrm{Ca}^{++}$Channel

\section{Complementary} actions

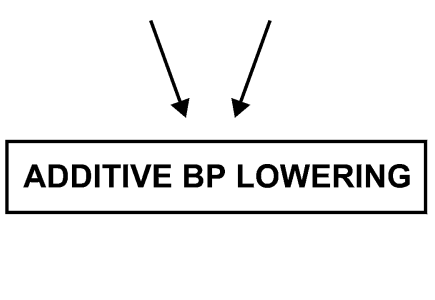

$\uparrow$ Arterial vasodilation

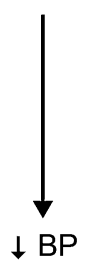

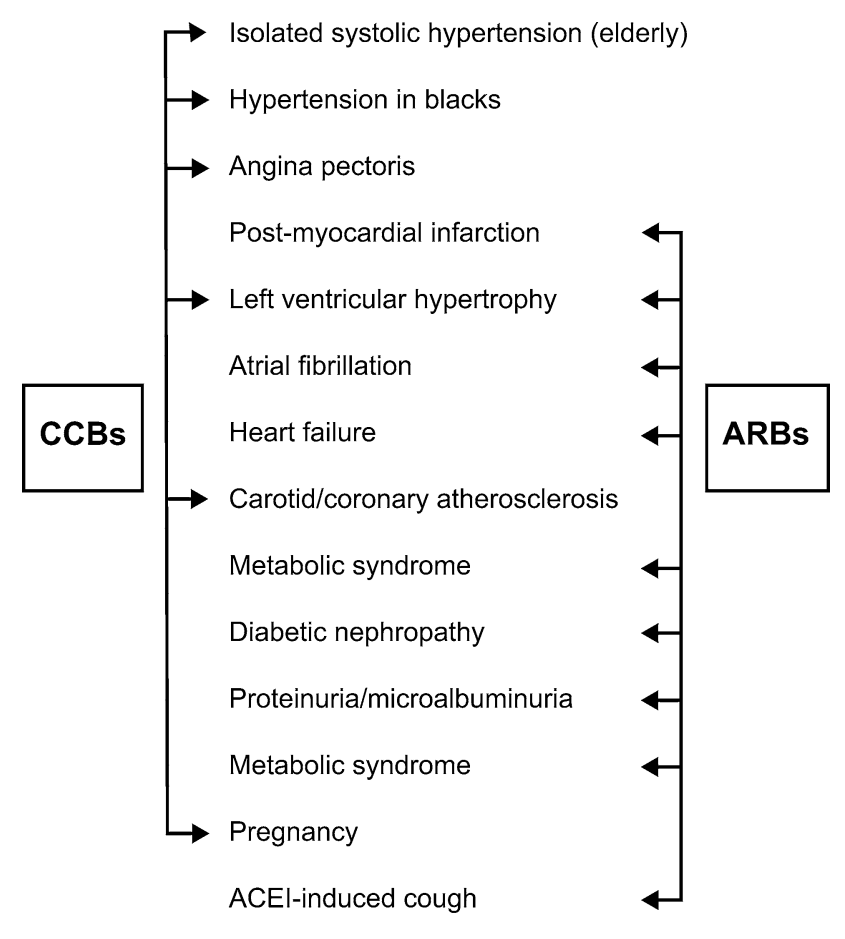

$\mathrm{ACEI}$, angiotensin-converting enzyme inhibitor.

Fig. 2 Conditions favoring the use of dihydropyridine calcium channel blockers (CCBs) and angiotensin receptor blockers (ARBs) according to guidelines for the management of hypertension. Reprinted with permission of Dove Medical Press Ltd, from Waeber and Ruilope [48]; permission conveyed through Copyright Clearance Center, Inc

identified a total of seven studies that included an efficacy and/or safety evaluation of combination amlodipine/valsartan in the non-white populations of interest [42, 53-58]. The authors were aware of and included an additional study that was not identified in the PubMed search [59]. In total, these studies comprised 1,111 black, 389 Hispanic/Latino, and 3,094 Asian patients with hypertension.

\subsection{Sub-Saharan African Blacks}

Even though hypertension hardly existed in black Africa in the first half of the 20th century [60], more recently, in those aged 65 years and over, hypertension has been shown to affect $30-60 \%$ of African blacks [61]. Moreover, this proportion is steadily approaching the $60-70 \%$ range in the USA for blacks of similar age [61]. Thus, reducing BP and controlling hypertension are critical factors in preventing CVD.

In the Newer versus Older Antihypertensive agents in African Hypertensive patients (NOAAH) trial, Odili and colleagues compared the BP-lowering efficacy of a combination of newer (without a diuretic) versus older (with a diuretic) antihypertensive agents in black patients with hypertension born and living in sub-Saharan Africa [62]. The NOAAH study compared two SPCs for control of BP in African patients 30-69 years of age (mean age 51 years) with stage 1 or 2 hypertension (systolic/diastolic BP: 140-179/90-109 $\mathrm{mmHg}$ ) and no more than two additional risk factors. After a 4-week wash-out period, 140 patients were randomized to once-daily bisoprolol/hydrochlorothiazide (HCTZ) 5/6.25 mg or amlodipine/valsartan $5 / 160 \mathrm{mg}$, with permitted up-titration of the bisoprolol and amlodipine doses to $10 \mathrm{mg}$ to achieve $\mathrm{BP}<140 / 90 \mathrm{mmHg}$ [53]. At randomization, the bisoprolol/HCTZ and amlodipine/valsartan groups were similar with respect to demographic characteristics, and the overall combined systolic/ diastolic BP was 153.9/91.5 mmHg. After randomization, 


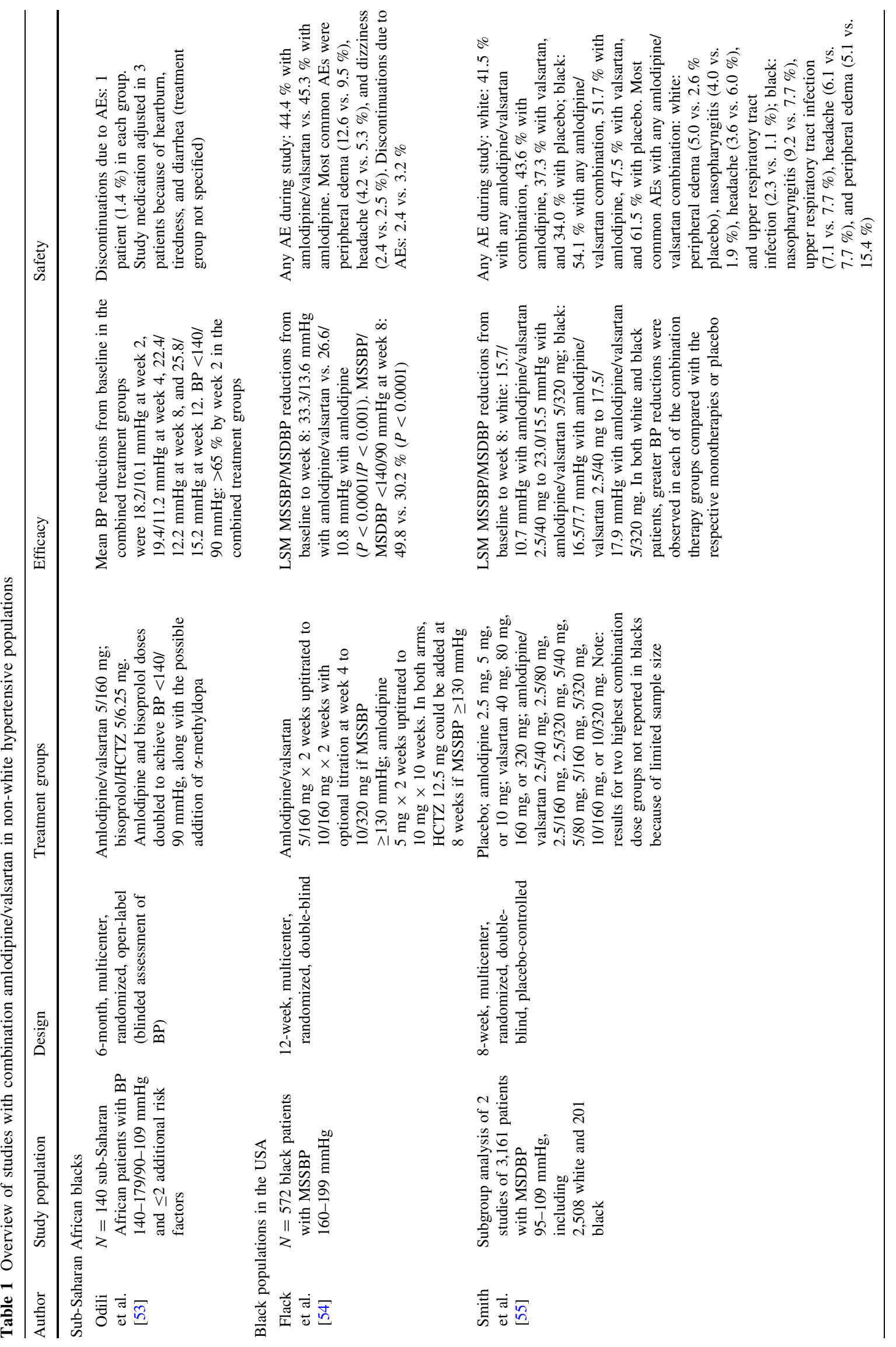




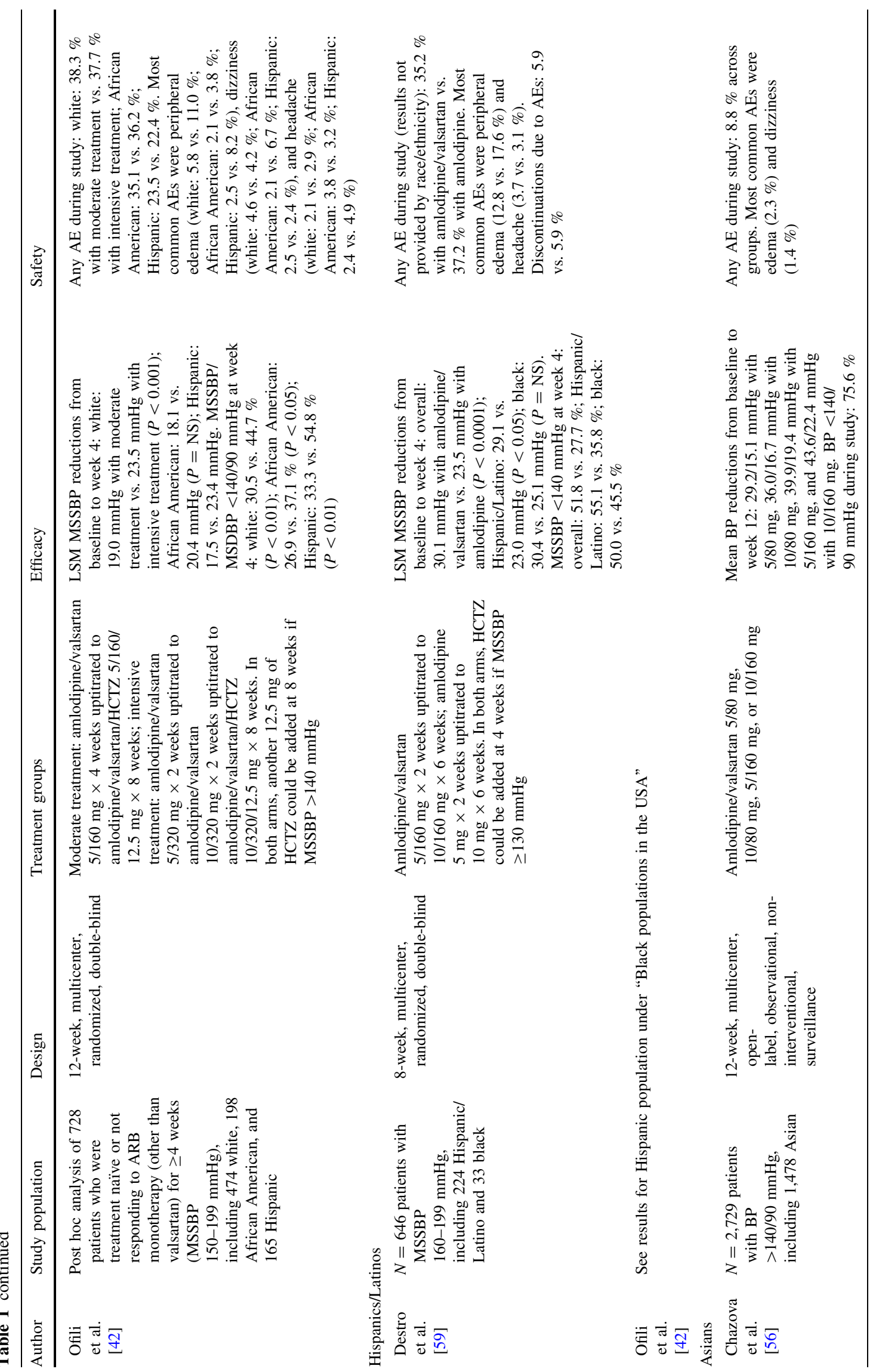




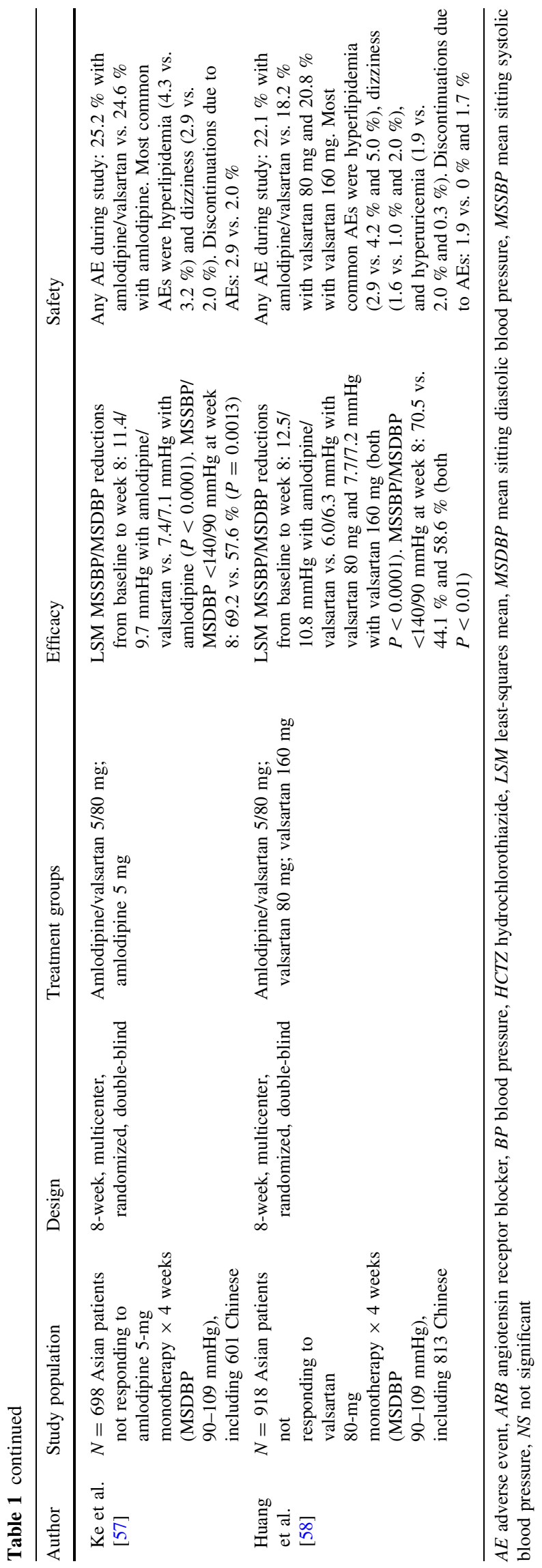

in both groups combined, BP dropped by $18.2 / 10.1 \mathrm{mmHg}$ at week $2(n=122), 19.4 / 11.2 \mathrm{mmHg}$ at week 4 $(n=109), 22.4 / 12.2 \mathrm{mmHg}$ at week $8(n=57)$, and $25.8 /$ $15.2 \mathrm{mmHg}$ at week $12(n=49)$. The BP control rate of $<140 / 90 \mathrm{mmHg}$ was $>65 \%$ by week 2 . Thus, NOAAH confirmed that SPC therapy can achieve BP control quickly in black patients born and living in sub-Saharan Africa and that randomized clinical trials of antihypertensive drugs in this indigenous population are feasible [53].

Although most studies have been done in blacks of African descent in the USA, there are data suggesting that an increase in the incidence of hypertension in blacks living in sub-Saharan Africa is leading to an increase in heart failure and CVD. In a recent (2012) study by Damasceno and colleagues, a prospective, multicenter, observational survey collected data on patients with acute heart failure (AHF) who had been admitted to 12 university hospitals in nine African countries (Sub-Saharan Africa Survey of Heart Failure [THESUS-HF]) [63]. The THESUS-HF survey enrolled 1,006 patients presenting with AHF between 2007 and 2010; mean age was 52.3 years, $50.8 \%$ were women, the predominant race was black African $(98.5 \%)$, and mean left ventricular ejection fraction was $39.5 \%$. The most common reason for heart failure was noted to be hypertension (45.4\%), while rheumatic heart disease $(14.3 \%)$ and ischemic heart disease $(7.7 \%)$ were not as commonly documented causes of AHF. The median hospital stay was 7 days, with an in-hospital mortality of $4.2 \%$ and an estimated 180-day mortality of $17.8 \%$ (95\% confidence interval 15.4-20.6). Overall, the THESUS-HF survey demonstrated that in African patients, AHF is primarily due to a non-ischemic cause, most commonly hypertension; occurs equally among genders, usually in middle-aged adults; and is associated with high mortality.

\subsection{African Americans}

The EXforge evaluation in Stage Two hypertensives of AfricaN Descent (EX-STAND) study was a 12-week, multicenter, double-blind, prospective, parallel-group trial of 572 black patients (mean age 53 years) with stage 2 hypertension (mean sitting systolic blood pressure [MSSBP] 160-199 mmHg) in the USA [54]. Patients were randomized to either combination amlodipine/valsartan $5 / 160 \mathrm{mg}$ or amlodipine 5-mg monotherapy. At 2 weeks, doses were force-titrated to $10 / 160 \mathrm{mg}$ and $10 \mathrm{mg}$, respectively. At 4 weeks, there was optional up-titration to $10 / 320 \mathrm{mg}$ in the combination-therapy arm if MSSBP was $\geq 130 \mathrm{mmHg}$. The combination of amlodipine/valsartan attained greater and faster reductions in BP: by week 8, combination amlodipine/valsartan significantly lowered MSSBP more than monotherapy (33.3 vs. $26.6 \mathrm{mmHg}$; 
$P<0.0001)$. A BP goal of $<140 / 90 \mathrm{mmHg}$ was achieved by 49.8 and $30.2 \%$ of patients, respectively $(P<0.0001)$.

A subgroup analysis of two 8-week, multicenter, randomized, double-blind, placebo-controlled studies $(n=$ 3,161 ) included 2,508 white patients (mean age 56 years) and 201 black patients (mean age 50 years) with stage 1 or 2 hypertension (mean sitting diastolic blood pressure [MSDBP] 95-109 mmHg) [55]. Patients received amlodipine monotherapy, valsartan monotherapy, or a combination of these agents at various dosages (Table 1). Combination therapy was significantly more effective in lowering BP than treatment with the respective monotherapies. In blacks, the greatest reduction in MSDBP was seen with amlodipine/valsartan 5/320 mg (17.9 mmHg), which was consistent with the reduction seen in whites (15.5 mmHg).

In a post hoc analysis of patients with hypertension enrolled in a 12-week, multicenter, randomized, double-blind clinical trial (EXforge TaRget Achievement [EXTRA]), treatment responses with combination amlodipine/valsartan $10 / 320 \mathrm{mg}$ versus amlodipine/valsartan $5 / 160 \mathrm{mg}$ were evaluated among a diverse cohort (474 white, 198 black, and 165 Hispanic individuals ranging in age from a mean of 51-57 years) [42]. Patients were treatment naïve or nonresponders (MSSBP 150-199 $\mathrm{mmHg}$ ) to angiotensin receptor blocker monotherapy (other than valsartan). Regardless of race or ethnic background, results demonstrated that more intensive dosage treatment provided greater BP lowering versus moderate treatment. In blacks, moderate treatment for 4 weeks (before addition of HCTZ) lowered MSSBP by $18.1 \mathrm{mmHg}$ and allowed $26.9 \%$ of patients to achieve BP goal $(<140 / 90 \mathrm{mmHg})$, whereas intensive treatment lowered MSSBP by $20.4 \mathrm{mmHg}$ with $37.1 \%$ of patients attaining BP goal $(P=$ not significant $/ P<0.01)$. Further improvement in $\mathrm{BP}$ was seen with the addition of HCTZ.

Across all studies, the combination of amlodipine/valsartan was well tolerated (Table 1). Peripheral edema was reported at an incidence ranging from 2.1 to $12.6 \%$ in the black population, which was within the range reported in control patients (9.5-15.4\%). Other adverse events reported among blacks treated with amlodipine/valsartan included headache (3.2-6.1 vs. 5.3-7.7\% in controls) and dizziness (2.1-6.7 vs. $2.5 \%$ in controls).

\subsection{Hispanics/Latinos}

In the EXforge EFFicacy and Control in Treatment of Stage 2 hypertension (EX-EFFeCTS) study, the efficacy and safety of combination amlodipine/valsartan versus amlodipine alone were compared in 646 patients (mean age 58 years) with stage 2 hypertension (MSSBP $160-199 \mathrm{mmHg}$ ) [59]. In this 8-week, multicenter, randomized, double-blind study, approximately one third of the study population $(n=224$;
$34.7 \%$ ) was of Hispanic/Latino ethnicity. The initiating doses were amlodipine/valsartan $5 / 160 \mathrm{mg}$ or amlodipine $5 \mathrm{mg}$ for 2 weeks, with force-titration to amlodipine/valsar$\tan 10 / 160 \mathrm{mg}$ or amlodipine $10 \mathrm{mg}$, respectively, for an additional 6 weeks. At 4 weeks (primary endpoint), MSSBP demonstrated an improvement in Hispanic/Latino patients receiving amlodipine/valsartan compared with those receiving amlodipine alone $(-29.1$ vs. $-23.0 \mathrm{mmHg} ; P<0.05)$. An MSSBP $<140 \mathrm{mmHg}$ was achieved by 55.1 and $35.8 \%$ of Hispanic/Latino patients, respectively $(P$ value not reported).

The previously mentioned post hoc analysis by Ofili and colleagues included $165(22.7 \%)$ Hispanic patients [42]. In this population, treatment with combination amlodipine/ valsartan for 4 weeks lowered MSSBP by $17.5 \mathrm{mmHg}$ (moderate treatment) or $23.4 \mathrm{mmHg}$ (intensive treatment) $(P<0.01)$. Corresponding BP control rates were 33.3 and $54.8 \%(P<0.01)$. As in black people, the addition of HCTZ provided further antihypertensive efficacy.

In both of the above studies, efficacy results in Hispanic/ Latino patients were similar to those seen for other race groups and the overall population (Table 1). In addition, the combination of amlodipine/valsartan was well tolerated, providing support for use of this regimen in Hispanic/ Latino patients. The most commonly reported adverse event was peripheral edema: $8.2 \%$ with the intensive regimen and $2.5 \%$ with the moderate regimen in one study and $12.8 \%$ with combination therapy versus $17.6 \%$ with amlodipine monotherapy in the other study. Across both studies, headache was reported by $2.4-4.9 \%$ of patients receiving amlodipine/valsartan and $3.1 \%$ of patients receiving amlodipine alone.

\subsection{Asians}

Due to less-robust data in Asian Americans, clinical data are discussed for non-American Asian cohorts. Recently, an open-label, observational, non-interventional, surveillance study was designed to evaluate the safety and effectiveness of the amlodipine/valsartan combination [56]. There were 2,729 participants with systolic BP $>140$ $\mathrm{mmHg}$ and/or diastolic BP $>90 \mathrm{mmHg}$ from 298 centers around the world, including China, Malaysia, Pakistan, Bangladesh, Egypt, and Russia. The cohort was composed of $54.5 \%$ men, $54.2 \%$ Asian, and $44.6 \%$ white. Mean age was 57.9 years, baseline BP was $163.1 / 96.2 \mathrm{mmHg}$, and $86.5 \%$ had prior hypertension therapy that was discontinued. During the 12 weeks of treatment with amlodipine/ valsartan, there was a significant systolic/diastolic BP reduction of $33.2 / 16.9 \mathrm{mmHg}(P<0.0001)$, resulting in a substantially lower final BP reading of $129.9 / 79.3 \mathrm{mmHg}$. Additionally, Chazova and colleagues [56] demonstrated a dose-dependent effect with amlodipine/valsartan where the 
smallest BP reduction was $29.2 / 15.1 \mathrm{mmHg}$ with the $5 / 80$ $\mathrm{mg}$ dose $(P<0.0001)$ and the greatest $\mathrm{BP}$ reduction was $43.6 / 22.4 \mathrm{mmHg}$ with the $10 / 160-\mathrm{mg}$ dose $(P<0.0001)$. $\mathrm{BP}$ lowering was linked to the severity of baseline BP levels.

In an 8-week, multicenter, randomized, double-blind trial, Ke and colleagues [57] studied the effects of the SPC of amlodipine/valsartan compared with amlodipine alone in an Asian hypertensive population that was non-responsive (MSDBP 90-109 $\mathrm{mmHg}$ ) to amlodipine 5-mg monotherapy. Baseline characteristics were similar between treatment groups: the majority of patients were male $(65.1 \%)$ and Chinese $(86.4 \%)$; mean age was 53.8 years; and mean seated systolic/diastolic BP was 139.5/ $94.5 \mathrm{mmHg}$. After a 1-4-week washout period, a total of 698 patients were randomized to either amlodipine/valsartan 5/80 mg or amlodipine $5 \mathrm{mg}$. Results showed that the reduction in systolic/diastolic BP at the week 8 endpoint was significantly greater with amlodipine/valsartan than with amlodipine (11.4/9.7 vs. $7.4 / 7.1 \mathrm{mmHg}$; $P<0.0001$ ), with a correspondingly higher BP-control rate $(<140 / 90 \mathrm{mmHg}): 69.2$ versus $57.6 \% ; P=0.0013$.

Huang and colleagues [58] evaluated the efficacy of the SPC of amlodipine/valsartan in another 8-week, randomized, double-blind study of 918 Asian patients (mean age 52 years) with stage 1 or 2 hypertension (MSDBP $90-109 \mathrm{mmHg}$ ) from 30 centers in Asia who were not responding to valsartan 80-mg monotherapy. The patients were randomized to receive amlodipine/valsartan 5/80 mg $(n=308)$, valsartan $80 \mathrm{mg}$ $(n=307)$, or valsartan $160 \mathrm{mg}(n=303)$. Results at the week 8 endpoint revealed reductions in $\mathrm{BP}$ of $12.5 / 10.8 \mathrm{mmHg}$ for amlodipine/valsartan $5 / 80 \mathrm{mg}$, which were significantly greater than those for valsartan $80 \mathrm{mg}(6.0 / 6.3 \mathrm{mmHg})$ or valsartan $160 \mathrm{mg}(7.7 / 7.2 \mathrm{mmHg})(P<0.0001)$. Regardless of baseline $\mathrm{BP}$, at the week 8 endpoint, a significant proportion of patients achieved BP control with amlodipine/valsartan $5 / 80 \mathrm{mg}$ compared with the valsartan monotherapies (Table 1; $P<0.01$ for both comparisons).

As shown in Table 1, the combination of amlodipine/ valsartan was well tolerated across each of the above studies. Across the three studies identified in the Asian population assessments, the most commonly reported adverse event was hyperlipidemia (up to $4.3 \%$ of patients on amlodipine/valsartan vs. $3.2 \%$ on amlodipine monotherapy and 4.2-5.0 \% on valsartan monotherapy). Dizziness was the second most common adverse event, reported in 1.4-2.9\% of patients on combination therapy and 1.0-2.0\% on monotherapy.

\section{Conclusions}

Hypertension and its related morbidity and mortality affect a disproportionate number of black patients compared with white patients. Blacks, Hispanics/Latinos, and Asians especially need effective hypertension treatment and control, considering their high prevalence of comorbidities, including obesity, diabetes, and metabolic syndrome. Such high-risk patients are good candidates for RAAS-inhibitorbased combination therapy, including a thiazide-type diuretic or long-acting calcium channel blocker. Adherence and persistence to antihypertensive medication remain suboptimal, including in these non-white populations, with evidence suggesting improvement with the use of SPC therapy. Results of clinical trials in blacks, Hispanics/ Latinos, and Asians with stage 1 or 2 hypertension show that treatment with the combination of a dihydropyridine calcium channel blocker plus RAAS blocker (e.g., amlodipine/valsartan) is a reasonable choice for initial therapy or in patients who fail to respond to monotherapy. These drug classes have complementary mechanisms of action and, when used concomitantly, the magnitude of BP lowering in these non-white populations is generally comparable with that seen in non-Hispanic white patients. Although the clinical trial evidence is not examined in this review, if necessary, a diuretic can be added to the amlodipine/valsartan combination to further reduce BP, without compromising safety and tolerability [64, 65].

Although the focus of this article is on combination calcium channel blocker/RAAS blocker therapy (particularly, amlodipine/valsartan), treatment with a thiazide-type diuretic plus RAAS blocker is another effective approach for the treatment of hypertension, including in non-white hypertensive patients [66, 67]. The main concern with using thiazide-type diuretics has been tolerability, although lower doses are generally well tolerated [68]. Some evidence suggests that calcium channel blockers may provide greater regression of organ damage than thiazide diuretics, when used in combination with RAAS blockers [69, 70], and that combination calcium channel blocker/RAAS blocker therapy may reduce the risk of new-onset diabetes in hypertensive patients with metabolic syndrome [71, 72]. Furthermore, results of the Avoiding Cardiovascular events through COMbination therapy in Patients LIving with Systolic Hypertension (ACCOMPLISH) trial suggest that treatment with a calcium channel blocker plus RAAS blocker, relative to a thiazide diuretic plus RAAS blocker, may confer greater protection from cardiovascular events and renal disease progression in high-risk hypertensive patients $[73,74]$. Although the majority of patients enrolled in ACCOMPLISH were white, they had a high incidence of cardiovascular risk factors (e.g., diabetes [60\%], dyslipidemia [74\%], obesity [mean BMI $31 \mathrm{~kg} / \mathrm{m}^{2}$ ]) that are common in blacks, Hispanics/Latinos, and Asians. Further comparative studies are needed to determine optimal antihypertensive combinations in these minority populations. 
Our findings are not unique to combination amlodipine/ valsartan therapy. Similar results have been reported with other amlodipine/angiotensin receptor blocker SPC therapies in blacks and Hispanics/Latinos (e.g., amlodipine/ olmesartan [75], amlodipine/telmisartan [76]), although data in Asians are lacking with these other combinations. Of note, because of acculturation and certain health behaviors (e.g., diet, physical activity), it is not known whether the literature findings reported in Asian patients can be generalized to the Asian American population. Kaplan and colleagues [77] reported that the prevalence of hypertension among Asian immigrants increased with increasing length of residence in Canada, from $3 \%(0-4$ years $)$ to $7 \%$ (5-9 years) to $13 \%$ (10 or more years). A similar association was reported in a multiethnic cohort (white, black, Latino, and Asian) living in the USA, independent of confounders such as age, gender, race/ethnicity, level of education, smoking, alcohol intake, physical activity, BMI, and history of diabetes [78]. In addition, although BP reductions appear robust with combination amlodipine/valsartan, outcomes data comparing this treatment approach with other combination regimens are not available. Thus, the optimal cardiovascular outcome benefits during management of patients with amlodipine/valsartan and similar combinations cannot be determined at this time. Lastly, it is important to note that pharmacological therapy is not a substitute for lifestyle changes. Sodium restriction, smoking cessation, weight reduction, moderation of alcohol consumption, and a diet rich in fruits, vegetables, and low-fat dairy products have been shown to reduce BP, and should be implemented in all patients including those who require antihypertensive drug therapy $[4,79]$.

\begin{abstract}
Acknowledgments Drs. Ferdinand and Nasser wrote the manuscript. Technical assistance with editing, figure preparation, and styling of the manuscript for submission was provided by Michael S. McNamara, MS, CMPP, of Oxford PharmaGenesis Inc., and was funded by Novartis Pharmaceuticals Corporation. The authors were fully responsible for all content and editorial decisions and received no financial support or other form of compensation related to the development of this manuscript. The opinions expressed in the manuscript are those of the authors, and Novartis Pharmaceuticals Corporation had no influence on the contents.
\end{abstract}

Disclosures Dr. Ferdinand has received research support from Novartis Pharmaceuticals Corporation and AstraZeneca. He is a consultant or has received honoraria from AstraZeneca, Novartis Pharmaceuticals Corporation, Forest Labs, and Takeda. He has received payment for lectures from AstraZeneca, Novartis Pharmaceuticals Corporation, and Takeda. Dr. Nasser has nothing to disclose.

\section{Conflict of interest None.}

Open Access This article is distributed under the terms of the Creative Commons Attribution Noncommercial License which permits any noncommercial use, distribution, and reproduction in any medium, provided the original author(s) and the source are credited.

\section{References}

1. Yoon PW, Gillespie CD, George MG, et al. Control of hypertension among adults-National Health and Nutrition Examination Survey, United States, 2005-2008. MMWR Morb Mortal Wkly Rep. 2012;61(Suppl):19-25.

2. Go AS, Mozaffarian D, Roger VL, et al. Heart disease and stroke statistics-2013 update: a report from the American Heart Association. Circulation. 2013;127:e6-245.

3. Messerli FH, Williams B, Ritz E. Essential hypertension. Lancet. 2007;370:591-603.

4. Chobanian AV, Bakris GL, Black HR, et al. The Seventh Report of the Joint National Committee on Prevention, Detection, Evaluation, and Treatment of High Blood Pressure: the JNC 7 report. JAMA. 2003;289:2560-72.

5. Lewington S, Clarke R, Qizilbash N, et al. Age-specific relevance of usual blood pressure to vascular mortality: a meta-analysis of individual data for one million adults in 61 prospective studies. Lancet. 2002;360:1903-13.

6. Stamler R. Implications of the INTERSALT study. Hypertension. 1991;17(1 Suppl):I16-20.

7. Gu Q, Burt VL, Dillon CF, et al. Trends in antihypertensive medication use and blood pressure control among United States adults with hypertension: the National Health And Nutrition Examination Survey, 2001 to 2010. Circulation. 2012;126:2105-14.

8. Flack JM, Sica DA, Bakris G, et al. Management of high blood pressure in Blacks: an update of the International Society on Hypertension in Blacks consensus statement. Hypertension. 2010;56:780-800.

9. Guo F, He D, Zhang W, et al. Trends in prevalence, awareness, management, and control of hypertension among United States adults, 1999 to 2010. J Am Coll Cardiol. 2012;60:599-606.

10. Weir MR, Bakris GL, Weber MA, et al. Renal outcomes in hypertensive Black patients at high cardiovascular risk. Kidney Int. 2012;81:568-76.

11. Romero CX, Romero TE, Shlay JC, et al. Changing trends in the prevalence and disparities of obesity and other cardiovascular disease risk factors in three racial/ethnic groups of USA adults. Adv Prev Med. 2012;2012:172423.

12. Egan BM, Zhao Y, Axon RN. US trends in prevalence, awareness, treatment, and control of hypertension, 1988-2008. JAMA. 2010;303:2043-50.

13. Carson AP, Howard G, Burke GL, et al. Ethnic differences in hypertension incidence among middle-aged and older adults: the multi-ethnic study of atherosclerosis. Hypertension. 2011;57:1101-7.

14. Vivo RP, Krim SR, Cevik C, et al. Heart failure in Hispanics. J Am Coll Cardiol. 2009;53:1167-75.

15. Bahrami H, Kronmal R, Bluemke DA, et al. Differences in the incidence of congestive heart failure by ethnicity: the multi-ethnic study of atherosclerosis. Arch Intern Med. 2008;168:2138-45.

16. Daviglus ML, Talavera GA, Avilés-Santa ML, et al. Prevalence of major cardiovascular risk factors and cardiovascular diseases among Hispanic/Latino individuals of diverse backgrounds in the United States. JAMA. 2012;308:1775-84.

17. Park IU, Taylor AL. Race and ethnicity in trials of antihypertensive therapy to prevent cardiovascular outcomes: a systematic review. Ann Fam Med. 2007;5:444-52.

18. Hunt KJ, Resendez RG, Williams K, et al. All-cause and cardiovascular mortality among Mexican-American and non-Hispanic White older participants in the San Antonio Heart Study-evidence against the "Hispanic paradox". Am J Epidemiol. 2003;158:1048-57.

19. Kearney PM, Whelton M, Reynolds K, et al. Global burden of hypertension: analysis of worldwide data. Lancet. 2005;365:21723. 
20. Zhao Y, Lu F, Sun H, et al. Trends in hypertension prevalence, awareness, treatment, and control rates in Shandong Province of China. J Clin Hypertens (Greenwich). 2012;14:637-43.

21. Cai L, Liu A, Zhang L, et al. Prevalence, awareness, treatment, and control of hypertension among adults in Beijing, China. Clin Exp Hypertens. 2012;34:45-52.

22. Li H, Meng Q, Sun X, et al. Prevalence, awareness, treatment, and control of hypertension in rural China: results from Shandong Province. J Hypertens. 2010;28:432-8.

23. Dong GH, Sun ZQ, Zhang XZ, et al. Prevalence, awareness, treatment $\&$ control of hypertension in rural Liaoning province, China. Indian J Med Res. 2008;128:122-7.

24. Ramachandran A, Snehalatha C, Shetty AS, et al. Trends in prevalence of diabetes in Asian countries. World J Diabetes. 2012;3:110-7.

25. Qin X, Li J, Zhang Y, et al. Prevalence and associated factors of diabetes and impaired fasting glucose in Chinese hypertensive adults aged 45 to 75 years. PLoS One. 2012;7:e42538.

26. Zhang L, Zhang WH, Zhang L, et al. Prevalence of overweight/ obesity and its associations with hypertension, diabetes, dyslipidemia, and metabolic syndrome: a survey in the suburban area of Beijing, 2007. Obes Facts. 2011;4:284-9.

27. Adams AS, Uratsu C, Dyer W, et al. Health system factors and antihypertensive adherence in a racially and ethnically diverse cohort of new users. JAMA Intern Med. 2013;173:54-61.

28. Dezii CM. A retrospective study of persistence with single-pill combination therapy vs. concurrent two-pill therapy in patients with hypertension. Manag Care. 2001;10(2 Suppl):6-10.

29. Iskedjian M, Einarson TR, MacKeigan LD, et al. Relationship between daily dose frequency and adherence to antihypertensive pharmacotherapy: evidence from a meta-analysis. Clin Ther. 2002;24:302-16.

30. Hess G, Hill J, Lau H, et al. Medication utilization patterns and hypertension-related expenditures among patients who were switched from fixed-dose to free-combination antihypertensive therapy. P\&T. 2008;33:652-66.

31. Sever PS, Messerli FH. Hypertension management 2011: optimal combination therapy. Eur Heart J. 2011;32:2499-506.

32. Parati G, Ochoa JE, Bilo G. Blood pressure variability, cardiovascular risk, and risk for renal disease progression. Curr Hypertens Rep. 2012;14:421-31.

33. Sood N, Reinhart KM, Baker WL. Combination therapy for the management of hypertension: a review of the evidence. Am J Health Syst Pharm. 2010;67:885-94.

34. Wald DS, Law M, Morris JK, et al. Combination therapy versus monotherapy in reducing blood pressure: meta-analysis on 11,000 participants from 42 trials. Am J Med. 2009;122:290-300.

35. Malesker MA, Hilleman DE. Comparison of amlodipine/valsar$\tan$ fixed-dose combination therapy and conventional therapy. Manag Care. 2010;19:36-42.

36. Baser O, Andrews LM, Wang L, et al. Comparison of real-world adherence, healthcare resource utilization and costs for newly initiated valsartan/amlodipine single-pill combination versus angiotensin receptor blocker/calcium channel blocker free-combination therapy. J Med Econ. 2011;14:576-83.

37. Black HR. Triple fixed-dose combination therapy: back to the past. Hypertension. 2009;54:19-22.

38. Zeng F, Patel BV, Andrews L, et al. Adherence and persistence of single-pill ARB/CCB combination therapy compared to multiplepill ARB/CCB regimens. Curr Med Res Opin. 2010;26:2877-87.

39. Saunders E, Weir MR, Kong BW, et al. A comparison of the efficacy and safety of a beta-blocker, a calcium channel blocker, and a converting enzyme inhibitor in hypertensive blacks. Arch Intern Med. 1990;150:1707-13.

40. Weir MR, Gray JM, Paster R, et al. Differing mechanisms of action of angiotensin-converting enzyme inhibition in black and white hypertensive patients. The Trandolapril Multicenter Study Group. Hypertension. 1995;26:124-30.

41. Brewster LM, van Montfrans GA, Kleijnen J. Systematic review: antihypertensive drug therapy in black patients. Ann Intern Med. 2004;141:614-27.

42. Ofili EO, Oparil S, Giles T, et al. Moderate versus intensive treatment of hypertension using amlodipine/valsartan and with the addition of hydrochlorothiazide for patients uncontrolled on angiotensin receptor blocker monotherapy: results in racial/ethnic subgroups. J Am Soc Hypertens. 2011;5:249-58.

43. Cravedi P, Ruggenenti P, Remuzzi G. Which antihypertensive drugs are the most nephroprotective and why? Expert Opin Pharmacother. 2010;11:2651-63.

44. Verdecchia P, Gentile G, Angeli F, et al. Beyond blood pressure: evidence for cardiovascular, cerebrovascular, and renal protective effects of renin-angiotensin system blockers. Ther Adv Cardiovasc Dis. 2012;6:81-91

45. Agodoa LY, Appel L, Bakris GL, et al. Effect of ramipril vs amlodipine on renal outcomes in hypertensive nephrosclerosis: a randomized controlled trial. JAMA. 2001;285:2719-28.

46. Wright JT Jr, Bakris G, Greene T, et al. Effect of blood pressure lowering and antihypertensive drug class on progression of hypertensive kidney disease: results from the AASK trial. JAMA. 2002;288:2421-31.

47. Neutel JM. Complementary mechanisms of angiotensin receptor blockers and calcium channel blockers in managing hypertension. Postgrad Med. 2009;121:40-8.

48. Waeber B, Ruilope LM. Amlodipine and valsartan as components of a rational and effective fixed-dose combination. Vasc Health Risk Manag. 2009;5:165-74.

49. Cohn JN, Tognoni G. A randomized trial of the angiotensinreceptor blocker valsartan in chronic heart failure. N Engl J Med. 2001;345:1667-75.

50. Pfeffer MA, McMurray JJ, Velazquez EJ, et al. Valsartan, captopril, or both in myocardial infarction complicated by heart failure, left ventricular dysfunction, or both. $\mathrm{N}$ Engl J Med. 2003;349:1893-906.

51. Julius S, Kjeldsen SE, Weber M, et al. Outcomes in hypertensive patients at high cardiovascular risk treated with regimens based on valsartan or amlodipine: the VALUE randomised trial. Lancet. 2004;363:2022-31.

52. Nissen SE, Tuzcu EM, Libby P, et al. Effect of antihypertensive agents on cardiovascular events in patients with coronary disease and normal blood pressure: the CAMELOT study: a randomized controlled trial. JAMA. 2004;292:2217-25.

53. Odili AN, Ezeala-Adikaibe B, Ndiaye MB, et al. Progress report on the first sub-Saharan Africa trial of newer versus older antihypertensive drugs in native black patients. Trials. 2012;13:59.

54. Flack JM, Calhoun DA, Satlin L, et al. Efficacy and safety of initial combination therapy with amlodipine/valsartan compared with amlodipine monotherapy in black patients with stage 2 hypertension: the EX-STAND study. J Hum Hypertens. 2009;23:479-89.

55. Smith TR, Philipp T, Vaisse B, et al. Amlodipine and valsartan combined and as monotherapy in stage 2, elderly, and black hypertensive patients: subgroup analyses of 2 randomized, placebocontrolled studies. J Clin Hypertens (Greenwich). 2007;9:355-64.

56. Chazova IE, Dongre N, Vigdorchik AV. Real-life safety and effectiveness of amlodipine/valsartan combination in the treatment of hypertension. Adv Ther. 2011;28:134-49.

57. Ke Y, Zhu D, Hong H, et al. Efficacy and safety of a single-pill combination of amlodipine/valsartan in Asian hypertensive patients inadequately controlled with amlodipine monotherapy. Curr Med Res Opin. 2010;26:1705-13.

58. Huang J, Sun NL, Hao YM, et al. Efficacy and tolerability of a single-pill combination of amlodipine/valsartan in Asian 
hypertensive patients not adequately controlled with valsartan monotherapy. Clin Exp Hypertens. 2011;33:179-86.

59. Destro M, Luckow A, Samson M, et al. Efficacy and safety of amlodipine/valsartan compared with amlodipine monotherapy in patients with stage 2 hypertension: a randomized, double-blind, multicenter study: the EX-EFFeCTS Study. J Am Soc Hypertens. 2008;2:294-302.

60. Donnison CP. Blood pressure in the African native: its bearing on the aetiology of hyperpiesia and arteriosclerosis. Lancet. 1929;213:6-7.

61. Opie LH, Seedat YK. Hypertension in sub-Saharan African populations. Circulation. 2005;112:3562-8.

62. Odili AN, Richart T, Thijs L, et al. Rationale and design of the Newer Versus Older Antihypertensive Agents in African Hypertensive Patients (NOAAH) trial. Blood Press. 2011;20:256-66.

63. Damasceno A, Mayosi BM, Sani M, et al. The causes, treatment, and outcome of acute heart failure in 1006 Africans from 9 countries. Arch Intern Med. 2012;172:1386-94.

64. Calhoun DA, Lacourcière Y, Chiang YT, et al. Triple antihypertensive therapy with amlodipine, valsartan, and hydrochlorothiazide: a randomized clinical trial. Hypertension. 2009;54:32-9.

65. Lacourcière Y, Crikelair N, Glazer RD, et al. 24-Hour ambulatory blood pressure control with triple-therapy amlodipine, valsartan and hydrochlorothiazide in patients with moderate to severe hypertension. J Hum Hypertens. 2011;25:615-22.

66. Wright JT Jr, Lacourcière Y, Samuel R, et al. 24-Hour ambulatory blood pressure response to combination valsartan/hydrochlorothiazide and amlodipine/hydrochlorothiazide in stage 2 hypertension by ethnicity: the EVALUATE study. J Clin Hypertens (Greenwich). 2010;12:833-40.

67. Lai WT, Park JE, Dongre N, et al. Efficacy, safety, and tolerability of valsartan/hydrochlorothiazide in Asian patients with essential hypertension. Adv Ther. 2011;28:427-38.

68. Ernst ME, Moser M. Use of diuretics in patients with hypertension. N Engl J Med. 2009;361:2153-64.

69. Klingbeil AU, Schneider M, Martus P, et al. A meta-analysis of the effects of treatment on left ventricular mass in essential hypertension. Am J Med. 2003;115:41-6.
70. Simon A, Gariépy J, Moyse D, et al. Differential effects of nifedipine and co-amilozide on the progression of early carotid wall changes. Circulation. 2001;103:2949-54.

71. Bakris G, Molitch M, Hewkin A, et al. Differences in glucose tolerance between fixed-dose antihypertensive drug combinations in people with metabolic syndrome. Diabetes Care. 2006;29: 2592-7.

72. Martinez-Martin FJ, Rodriguez-Rosas H, Peiro-Martinez I, et al. Olmesartan/amlodipine vs olmesartan/hydrochlorothiazide in hypertensive patients with metabolic syndrome: the OLAS study. J Hum Hypertens. 2011;25:346-53.

73. Jamerson K, Weber MA, Bakris GL, et al. Benazepril plus amlodipine or hydrochlorothiazide for hypertension in high-risk patients. N Engl J Med. 2008;359:2417-28.

74. Bakris GL, Sarafidis PA, Weir MR, et al. Renal outcomes with different fixed-dose combination therapies in patients with hypertension at high risk for cardiovascular events (ACCOMPLISH): a prespecified secondary analysis of a randomised controlled trial. Lancet. 2010;375:1173-81.

75. Erdine S. Olmesartan/amlodipine: blood pressure lowering and beyond in special populations. Ther Adv Cardiovasc Dis. 2012;6:31-44.

76. Guthrie RM, Dahlöf B, Jamerson KA, et al. Efficacy and tolerability of telmisartan plus amlodipine in added-risk hypertensive patients. Curr Med Res Opin. 2011;27:1995-2008.

77. Kaplan MS, Chang C, Newsom JT, et al. Acculturation status and hypertension among Asian immigrants in Canada. J Epidemiol Community Health. 2002;56:455-6.

78. Teppala S, Shankar A, Ducatman A. The association between acculturation and hypertension in a multiethnic sample of US adults. J Am Soc Hypertens. 2010;4:236-43.

79. Mancia G, De Backer G, Dominiczak A, et al. 2007 Guidelines for the management of arterial hypertension: The Task Force for the Management of Arterial Hypertension of the European Society of Hypertension (ESH) and of the European Society of Cardiology (ESC). Eur Heart J. 2007;28:1462-536. 